\title{
Desempenho e orientação do crescimento do pepino japonês em ambiente protegido
}

\author{
Adalberto Santi1 ${ }^{1,2}$; Walcylene LMP Scaramuzza²; Danilo MJ Soares'; José Fernando Scaramuzza²; \\ Rivanildo Dallacort $^{1}$; Willian Krause ${ }^{1}$; Rafael Cesar Tieppo ${ }^{1}$ \\ ${ }^{1}$ UNEMAT-Campus Tangará da Serra, Depto. Agronomia, C. Postal 379, 78300-000 Tangará da Serra-MT; ${ }^{2}$ UFMT-FAMEV, Progr. Pós- \\ graduação Lato Sensu em Agricultura Tropical; adalbertosanti@unemat.br; walcylene@cpd.ufmt.br; danilo_maturano@hotmail.com; \\ jscaramuzza@uol.com.br; rdallacort@gmail.com; krause@unemat.br; rafaeltieppo@yahoo.com.br
}

\section{RESUMO}

Avaliou-se a produção de pepino japonês Tsuyataro, com diferentes métodos de orientação do crescimento das hastes, a partir do controle de brotações laterais das hastes e do número de hastes por planta, realizados através da poda. O trabalho foi desenvolvido no período de outubro a dezembro de 2010, em ambiente protegido em Tangará da Serra-MT, adotando-se o delineamento em blocos casualizados, distribuídos em esquema fatorial $2 \times 3$. O primeiro fator foi constituído de desbrota, ou seja, realização ou não da retirada dos ramos laterais das hastes e o segundo fator foi constituído pelo controle do número de hastes por planta: uma, duas e três hastes/planta, em cinco repetições. Foram avaliadas as características número de frutos total e comercial; taxa de frutos comerciais, comprimento, diâmetro, relação comprimento/diâmetro do fruto, produtividade total e comercial de frutos por planta; e massa média dos frutos do pepino. A condução da haste principal sem a retirada dos ramos laterais foi o tratamento que apresentou superioridade com relação ao número de frutos total e comercial por planta $(19,4$ e 16,0), e também maior produtividade total e comercial de frutos $(4.235,8$ e 3.438,3 g/planta). Já a poda das brotações laterais promoveu aumento no comprimento, diâmetro e na massa média dos frutos do pepino de 24,5 para 25,1 $\mathrm{cm} ; 3,4$ para $3,5 \mathrm{~cm}$ e 212,1 para 228,3 g/fruto, respectivamente.

Palavras-chave: Cucumis sativus, poda, brotação lateral, hastes/ planta, manejo de condução.

\begin{abstract}
Performance and growth conduction of Japanese cucumber in protected environment

The production of the Japanese cucumber Tsuyataro was evaluated using methods of stems growth conduction, controlling the lateral buds and number of stems per plant, through pruning. The research was carried out from October to December 2010, in a protected environment in Tangará da Serra, Mato Grosso state, Brazil, using a randomized blocks design, with five replications, in a factorial scheme $(2 \times 3)$. The first factor was the pruning, i.e., removal or not of lateral stems and the second factor was constituted of the control of number of stems: one, two and three stems per plant, with five replications. We evaluated the following characteristics: total and marketable number of fruits, commercial fruits rate, fruit length, fruit diameter, fruit length/diameter ratio, total and marketable yield of fruit per plant and fruit average weight. The treatment with conduction of the main stem without removal of lateral buds had better performance on total and marketable number of fruits per plant (19.4 and 16.0) and higher total and marketable yield of fruits (4,235.8 and 3,438.3 g per plant). The pruning of lateral buds provided increase in length, diameter and average mass of cucumber fruits of 24.5 to $25.1 \mathrm{~cm} ; 3.4$ to $3.5 \mathrm{~cm}$ and 212.1 to $228.3 \mathrm{~g}$ per fruit, respectively.
\end{abstract}

Keywords: Cucumis sativus, pruning, lateral buds, stem/plant, conduction management.

(Recebido para publicação em 5 de setembro de 2012; aceito em 17 de outubro de 2013) (Received on September 5, 2012; accepted on October 17, 2013)

\begin{abstract}
A s cucurbitáceas representam um grande volume de hortaliças comercializadas no Brasil. Incluem várias espécies que se destacam economicamente no abastecimento nacional pela ampla aceitação popular como o melão, melancia e abóboras (Filgueira, 2008). Em geral, as cucurbitáceas são produzidas em quantidades relativamente pequenas para consumo local e não costumam figurar nas estatísticas de produção de forma mais significativa, embora constituam itens importantes na dieta alimentar de muitos povos, na medida em que uma ou mais espécies sempre estão presentes nas áreas de
\end{abstract}

cultivo, sejam em escala comercial ou não. No Brasil o pepino (Cucumis sativus) apresenta uma produção de 215.117 toneladas (aproximadamente 4,4\% da produção nacional de hortaliças), a região centro-oeste contribui com uma produção de 19.723 toneladas (IBGE, 2006).

$\mathrm{O}$ pepino encontra-se entre as hortaliças de frutos com maior interesse comercial no Brasil. É muito apreciado e consumido em todo o país, na forma de fruto imaturo em saladas, curtido em salmoura ou vinagre na forma de picles e raramente maduro e cozido. Além do valor econômico e alimentar, o cultivo do pepino também tem grande importância social, na geração de empregos diretos e indiretos, pois demanda grande quantidade de mão-de-obra, desde o cultivo até a comercialização (Fontes \& Puiatti, 2005; Filgueira, 2008).

Através do cultivo em ambiente protegido é possível obter aumento nos rendimentos, bem como um produto de melhor qualidade para comercialização, principalmente fora das épocas tradicionais de cultivo na região, minimizando o efeito da sazonalidade de produção, além de possibilitar o controle parcial de fatores responsáveis pelo crescimento e desenvolvimento das plantas. $\mathrm{O}$ cultivo 
no interior do ambiente deve aproveitar ao máximo a área disponível; neste sentido empregam-se práticas fitotécnicas tais como tutoramento, arranjos de plantas e o uso de distintos tipos de poda, de acordo com a espécie cultivada (Martins et al., 1995; Pereira et al., 2003; Queiroga et al., 2008; Duarte \& Peil, 2010).

A arquitetura das plantas depende de correlações de crescimento entre suas várias partes, sendo que o crescimento de ramos laterais está geralmente, sob controle do ápice vegetativo. Deste modo, tanto o grau de ramificação quanto o estímulo do crescimento lateral e desenvolvimento do ramo principal, parecem ser função da dominância apical (Taiz \& Zeiger, 2004).

Os frutos do pepineiro dependem diretamente do compartimento vegetativo da planta, que é responsável pela produção dos assimilados. A maximização da produção de frutos é obtida quando se atinge a produção potencial de assimilados em nível de planta inteira e em seguida aloca-se para os frutos a maior fração possível desses. Uma das formas de manejo da produção e distribuição dos assimilados é através da poda (Schvambach et al., 2002).

A poda vem sendo cada vez mais utilizada em algumas hortaliças, com o objetivo de aumentar a produção e melhorar a qualidade dos frutos, influenciando assim no crescimento, arquitetura da planta e nos processos fisiológicos (Martins et al., 1995; Andriolo \& Falcão, 2000; Pereira et al., 2003).

As podas visam promover o equilíbrio fonte:dreno, via distribuição dos assimilados entre órgãos vegetativos e reprodutivos. Em cucurbitáceas a razão fonte:dreno pode ser alterada com a poda de hastes ou pelo raleio dos frutos, variando, respectivamente, número de folhas por planta, e consequentemente, a área foliar (fonte) e a demanda por fotoassimilados (dreno) (Queiroga et al., 2008). Podem ser obtidas ainda alterações na relação fonte:dreno, através de diferentes densidades de plantas, poda de brotações laterais, pela desfolha (Barni et al., 2003; Duarte et al., 2008). Peil \& Gálvez (2005) relataram que existem limites para a fração de assimilados que pode ser desviada para os frutos, já que as plantas necessitam destinar quantidade suficiente para os órgãos vegetativos, a fim de manter a sua capacidade produtiva futura. Com isso, o balanço apropriado entre o aporte e a demanda de assimilados da planta tem grande importância para maximizar a produção, e pode ser obtido através de adequada relação fonte:dreno (Duarte \& Peil, 2010).

No entanto, essa prática é de utilidade controvertida e tem sido questionada em função de diferentes resultados obtidos em pesquisas (Fontes \& Puiatti, 2005; Filgueira, 2008). Filgueira (2008) relatou ainda que os benefícios da poda se manifestam em algumas cultivares e não em todas, e que com o surgimento de novas cultivares, que produzem plantas com diferentes arquiteturas, o efeito da poda deveria ser novamente pesquisado. Pois, devido a diferentes tipos de expressão da floração do pepino, ou seja, ginóico, andromonóico e monóicos, observa-se recomendações de podas conforme a posição da flor na haste principal, tem-se ainda efeito da radiação solar, temperatura, umidade, nutrição da planta, entre outros fatores que poderão afetar direta ou indiretamente na viabilidade da poda.

Diante desse contexto, objetivou-se avaliar a produção de pepino japonês Tsuyataro em ambiente protegido e com o uso de diferentes métodos de condução de plantas, através da poda da brotação lateral (ramos ladrões) e do número de hastes/planta, no município de Tangará da Serra-MT.

\section{MATERIAL E MÉTODOS}

O experimento foi realizado na área experimental da Universidade do Estado de Mato Grosso, Campus Universitário de Tangará da Serra (14³7'10'S; 57²9'09'O; $320 \mathrm{~m}$ de altitude), no período 01 de outubro a 07 de dezembro de 2010. O solo utilizado é classificado como Latossolo vermelho distroférrico, textura argilosa e relevo suavemente ondulado (EMBRAPA, 2006). O clima da região é caracterizado por precipitação média anual de $1.800 \mathrm{~mm}$ e temperatura média anual de $24,4^{\circ} \mathrm{C}$ (Dallacort et al., 2011).

O estudo foi realizado no interior de uma estrutura de proteção, modelo túnel alto, com 21,0 m de comprimento; 5,20 m de largura, contendo 2,30 $\mathrm{m}$ de pé-direito e coberta com película de polietileno transparente de baixa densidade aditivada anti UV de 100 micras de espessura, disposta no sentido leste oeste geográfico. O sistema de irrigação adotado foi gotejamento, através de tubo gotejador, onde manteve-se a umidade do solo próxima à capacidade de campo.

A cultivar de pepineiro utilizada foi o híbrido Tsuyataro, pertencente ao grupo japonês de característica partenocárpica. A semeadura foi realizada diretamente no local de condução, na profundidade de $2 \mathrm{~cm}$, utilizando duas sementes por cova. O espaçamento adotado foi de 1,0 $\mathrm{m}$ entre linhas e 0,50 $\mathrm{m}$ entre plantas. Sete dias após a emergência das plântulas, as mesmas foram desbastadas, deixando-se apenas uma planta por cova.

O solo utilizado no experimento apresentou os seguintes valores na profundidade de $20 \mathrm{~cm}: \mathrm{pH}\left(\mathrm{Ca} \mathrm{Cl}_{2}\right)=4,7$; $\mathrm{MO}=41 \mathrm{~g} \mathrm{dm}^{-3} ; \mathrm{P}$ (resina) $=6 \mathrm{mg} \mathrm{dm}^{-3}$; $\mathrm{K}=0,8 \mathrm{mmol}_{\mathrm{c}} \mathrm{dm}^{-3} ; \mathrm{Ca}=14 \mathrm{mmol}_{\mathrm{c}} \mathrm{dm}^{-3}$; $\mathrm{Mg}=7 \mathrm{mmol}_{\mathrm{c}} \mathrm{dm}^{-3} ; \mathrm{H}+\mathrm{Al}=46 \mathrm{mmol}_{\mathrm{c}}$ $\mathrm{dm}^{-3} ; \mathrm{Al}=2 \mathrm{mmol} \mathrm{dm}^{-3} ; \mathrm{S}=16 \mathrm{mg} \mathrm{dm}^{-3}$; $\mathrm{B}=0,22 \mathrm{mg} \mathrm{dm}^{-3} ; \mathrm{Fe}=19,8 \mathrm{mg} \mathrm{dm}^{-3}$; $\mathrm{Mn}=11,3 \mathrm{mg} \mathrm{dm}^{-3} ; \mathrm{Cu}=2,3 \mathrm{mg} \mathrm{dm}^{-3}$; $\mathrm{Zn}=0,1 \mathrm{mg} \mathrm{dm}{ }^{-3}$; argila $=561 \mathrm{~g} \mathrm{~kg}^{-1}$; silte $=183 \mathrm{~g} \mathrm{~kg}^{-1}$ e areia $=256 \mathrm{~g} \mathrm{~kg}^{-1}$. As adubações foram efetuadas conforme recomendações para a cultura do pepino (Filgueira, 2008), baseada nos resultados da análise de solo citados acima. Foram aplicados um total de $120 \mathrm{~kg} \mathrm{ha}^{-1}$ de nitrogênio $(\mathrm{N}), 300 \mathrm{~kg} \mathrm{ha}^{-1}$ de $\mathrm{P}_{2} \mathrm{O}_{5}$ e $200 \mathrm{~kg} \mathrm{ha}^{-1}$ de $\mathrm{K}_{2} \mathrm{O}$, sendo no plantio aplicado todo o fósforo (P) e $30 \%$ do $\mathrm{N}$ e $40 \%$ do potássio (K). O restante do $\mathrm{N}$ e $\mathrm{K}$ foram divididos em três parcelas aos 15,20 e 40 dias após o plantio. Para fornecimento de N, P e K foram utilizados: uréia, superfosfato simples e cloreto de potássio, respectivamente.

As plantas foram conduzidas com fitilhos de ráfia dispostos verticalmente, até a altura de aproximadamente 2,0 m, onde então foram presas ao fio de arame estendido horizontalmente ao longo do ambiente protegido.

O delineamento experimental utilizado foi em blocos casualizados, em esquema fatorial $2 \times 3$, com cinco repeti- 
ções. O primeiro fator é a realização ou não da poda dos ramos laterais na planta e o segundo fator número de hastes por planta: uma haste por planta (HP), duas hastes por planta (DHP) e três hastes por planta (THP), proporcionando duas hastes $/ \mathrm{m}^{2}$, quatro hastes $/ \mathrm{m}^{2}$ e seis hastes/ $\mathrm{m}^{2}$, respectivamente. Realizou-se a poda apical das hastes ao atingirem 2,0 m de altura. Cada unidade experimental constou de uma linha com seis plantas, sendo que as quatro plantas centrais constituíram a área útil da parcela, totalizando 30 unidades experimentais. Vale ressaltar que nos tratamentos em que se realizou a condução das hastes laterais, foi realizada a poda do meristema apical das brotações, a partir do quinto nó para aparecimento de hastes laterais, já a partir da base da planta.

O controle de plantas daninhas foi realizado por meio de capina e arranquio manual, evitando a concorrência de plantas daninhas na utilização de água, luz, nutrientes e espaço. O controle fitossanitário da Diaphania nitidalis foi realizado no período de frutificação, através de duas aplicações de deltametrina na dosagem de $0,75 \mathrm{~g}$ de i.a./100L de água.

A colheita foi iniciada aos 43 dias após a semeadura, mantendo-se periodicidade de duas a três colheitas semanais. A última colheita foi realizada aos 67 dias após a semeadura. Os frutos foram colhidos, com aproximadamente $20 \mathrm{~cm}$ de comprimento (Cardoso, 2007; Lalla et al., 2010).

Foram avaliadas as características: número de frutos totais (NFT) (contagem acumulada de frutos colhidos na área útil da unidade experimental e ao final dividido pelo total de plantas na área útil); número de frutos comerciais (NFC) \{contagem acumulada de frutos comerciais colhidos na área útil da unidade experimental e ao final dividido pelo total de plantas na área útil [foram considerados frutos comerciais aqueles sem defeitos aparentes e retilíneos, conforme classificação da CEASAMINAS (2010)] $;$; taxa de frutos comerciais (TFC), dada pela equação, $T F C=\frac{N F C}{N F T} .100 \quad$ onde:

$\mathrm{TFC}=$ Taxa frutos comerciais $(\%)$; $\mathrm{NFC}=$ Número de frutos comerciais;
$\mathrm{NFT}=$ Número de frutos totais.

Ainda, foram avaliadas as características: comprimento de frutos (COM) (mediu-se com régua o comprimento longitudinal de todos os frutos obtidos na colheita acumulada da área útil, dividido pelo total de frutos, obtendo-se então o comprimento médio dos frutos dado em $\mathrm{cm}$ ); diâmetro de fruto (DF) (mediu-se com paquímetro duas secções transversais perpendiculares do fruto, com posterior média entre elas, em todos os frutos obtidos na colheita acumulada da área útil, dividido pelo total de frutos, obtendo-se então o diâmetro médio dos frutos, dados em $\mathrm{cm}$ ); relação entre (COM/DF); produção total (PT) (massa fresca dos frutos totais acumulados durante a colheita na área útil, dividida pelo número de plantas na mesma, dada em g planta-1); produção comercial (PC) (massa fresca dos frutos comerciais acumulados durante a colheita na área útil, dividida pelo número de plantas na mesma, dada em g planta $\left.{ }^{-1}\right)$; massa dos frutos (MMF) (massa fresca dos frutos comerciais acumulados durante a colheita na área útil, dividida pelo total de frutos comerciais na mesma, obtendo-se então a massa média dos frutos, dada em $g$ fruto $^{-1}$.

Os dados foram submetidos à análise de variância, sendo as médias comparadas pelo teste de Tukey, a 5\% de probabilidade, através da utilização do programa estatístico SISVAR 5.1 (Ferreira, 2008).

\section{RESULTADOS E DISCUSSÃO}

Houve interação entre os fatores controle das brotações laterais com o número de hastes por planta de pepino Tsuyataro, cultivado em ambiente protegido, para as variáveis: número de frutos total, número de frutos comerciais, taxa de frutos comerciais, produção total e produção comercial por planta (Tabela 1).

O manejo de condução determinado pelo crescimento livre, sem a retirada de brotações laterais e com uma haste por planta, que representa a condução geralmente utilizada para produção de pepino em ambiente protegido, apresentou melhor desempenho para número de frutos totais e comerciais em relação aos tratamentos com poda e manutenção de uma e duas hastes por planta e sem poda

Tabela 1. Interação entre métodos de condução de plantas realizada pela retirada dos ramos laterais e pelo número de hastes por planta, para o número de frutos totais por planta (NFT), comerciais por planta (NFC), taxa de frutos comerciais (TFC), produção total (PT) e produção comercial (PC) de frutos por planta [interaction between plant conduction methods through removal of lateral buds and plant stem number control, considering the total number of fruits per plant (NFT), number of marketable fruits per plant (NFC) marketable fruits rate (TFC), total production (PT) and marketable production (PC) of fruits per plant]. Tangará da Serra, UNEMAT, 2010.

\begin{tabular}{|c|c|c|c|c|c|c|}
\hline \multirow{2}{*}{ Características } & \multirow{2}{*}{$\begin{array}{l}\text { Ramos } \\
\text { laterais }\end{array}$} & \multicolumn{3}{|c|}{ Número de hastes por planta } & \multirow{2}{*}{ média } & \multirow{2}{*}{$\begin{array}{l}\text { CV } \\
(\%)\end{array}$} \\
\hline & & Uma & Duas & Três & & \\
\hline \multirow{2}{*}{$\begin{array}{l}\text { NFT } \\
\text { (planta) }\end{array}$} & Com & $11,7 \mathrm{Bb}$ & $12,4 \mathrm{Aab}$ & $14,5 \mathrm{Aa}$ & 12,9 & \multirow{2}{*}{9,6} \\
\hline & Sem & 19,4 Aa & $13,7 \mathrm{Ab}$ & $15,4 \mathrm{Ab}$ & 16,2 & \\
\hline \multirow{2}{*}{$\begin{array}{l}\text { NFT } \\
\text { (planta) }\end{array}$} & Con & $9,9 \mathrm{Bb}$ & 10,9 & $12,3 \mathrm{Aa}$ & 11,0 & \multirow{2}{*}{8,8} \\
\hline & Sem & $16,0 \mathrm{Aa}$ & $12,4 \mathrm{Ab}$ & $12,2 \mathrm{Ab}$ & 13,5 & \\
\hline \multirow{2}{*}{$\begin{array}{l}\text { TFC } \\
(\%)\end{array}$} & $\mathrm{Co}$ & 85,1 & 88, & $84,9 \mathrm{Aa}$ & 86,0 & \multirow{2}{*}{ 5, } \\
\hline & Sem & $82,6 \mathrm{Ab}$ & $90,0 \mathrm{Aa}$ & $78,8 \mathrm{Bb}$ & 83,8 & \\
\hline \multirow{2}{*}{$\begin{array}{l}\text { PT } \\
\left(\text { g planta }^{-1}\right)\end{array}$} & Com & $2.830,8 \mathrm{Bb}$ & $2.668,9 \mathrm{Ab}$ & $3.314,6 \mathrm{Aa}$ & $2.938,1$ & \multirow{2}{*}{10,0} \\
\hline & Sem & $4.235,8 \mathrm{Aa}$ & $2.885,8 \mathrm{Ab}$ & $3.280,9 \mathrm{Ab}$ & $3.470,9$ & \\
\hline \multirow{2}{*}{$\begin{array}{l}\text { PT } \\
\left(\text { g planta }^{-1}\right)\end{array}$} & Com & $2.379,6 \mathrm{Bb}$ & $2.367,7 \mathrm{Ab}$ & $2.807,8 \mathrm{Aa}$ & $2.518,4$ & \multirow{2}{*}{9,0} \\
\hline & Sem & $3.438,3 \mathrm{Aa}$ & $2.602,1 \mathrm{Ab}$ & $2.568,2 \mathrm{Ab}$ & $2.869,5$ & \\
\hline
\end{tabular}

*Médias seguidas da mesma letra maiúscula nas colunas e minúscula nas linhas, não diferem estatisticamente pelo teste Tukey a 5\% (means followed by same uppercase letters in columns and lowercase letters in the rows are not statistically different by Tukey test $5 \%$ ). 
Tabela 2. Efeito da eliminação dos ramos laterais no comprimento do fruto (COM), diâmetro do fruto (DF), na relação COM/DF e massa média dos frutos (MMF) de pepino japonês (effect of the lateral stems removal on length (COM), diameter (DF), COM/DF relation, and fruit weight average (MMF) of Japanese cucumber). Tangará da Serra, UNEMAT, 2010.

\begin{tabular}{|c|c|c|c|c|}
\hline \multirow{2}{*}{ Ramos laterais } & COM & DF & \multirow[t]{2}{*}{$\mathrm{COM} / \mathrm{DF}$} & \multirow{2}{*}{$\begin{array}{c}\text { MMF } \\
\text { (g fruto }^{-1} \text { ) }\end{array}$} \\
\hline & \multicolumn{2}{|c|}{ (cm) } & & \\
\hline Sem & $24,5 \mathrm{~B}$ & $3,4 \mathrm{~B}$ & $7,1 \mathrm{~A}$ & $212,1 \mathrm{~B}$ \\
\hline Com & $25,1 \mathrm{~A}$ & $3,5 \mathrm{~A}$ & $7,1 \mathrm{~A}$ & $228,3 \mathrm{~A}$ \\
\hline $\mathrm{CV}(\%)$ & 2,0 & 2,3 & 2,1 & 2,1 \\
\hline
\end{tabular}

*Médias seguidas da mesma letra, nas colunas, não diferem estatisticamente pelo teste Tukey a $5 \%$ (means followed by same letter in columns do not differ statistically by Tukey test, $5 \%$ ).

Tabela 3. Efeito dos métodos de condução de hastes no comprimento do pepino japonês $(\mathrm{COM})$, diâmetro do fruto (DF) e na relação COM/DF (effect of stem conduction methods on length of Japanese cucumber (COM), diameter (DF), COM/DF). Tangará da Serra, UNEMAT, 2010.

\begin{tabular}{lccc}
\hline \multirow{2}{*}{ Número de hastes por planta } & COM & DF & COM/DF \\
\cline { 2 - 3 } & \multicolumn{3}{c}{$\mathbf{( c m )}$} \\
\hline Uma & $25,1 \mathrm{~A}$ & $3,5 \mathrm{~A}$ & $7,1 \mathrm{~A}$ \\
Duas & $25,0 \mathrm{~A}$ & $3,4 \mathrm{~A}$ & $7,0 \mathrm{~A}$ \\
Três & $24,3 \mathrm{~B}$ & $3,5 \mathrm{~A}$ & $7,2 \mathrm{~A}$ \\
\hline CV $(\%)$ & 2,0 & 2,3 & 2,1 \\
\hline
\end{tabular}

*Médias seguidas da mesma letra na coluna não diferem estatisticamente pelo teste Tukey a $5 \%$ (means followed by same letter in columns do not differ statistically by Tukey test, $5 \%$ ).

e manutenção de uma e duas hastes por planta. Nota-se para o fator retirada de brotação lateral, que à medida que se restringiu o número de hastes/planta houve redução no número de frutos totais e comerciais.

Essa superioridade do tratamento sem poda das brotações laterais poderia ser devido ao maior número de brotações laterais, também verificado no manejo de condução de três hastes/planta com retirada das brotações laterais, com consequente produção de maior número de frutos totais e comerciais no manejo que se utilizou da eliminação dos brotos laterais.

Em melão, Pereira et al. (2003) constataram que plantas podadas obtiveram maior número de frutos e massa média em relação às não podadas e que, com o aumento na densidade de plantas houve o inverso, ou seja, menor número de frutos e massa média dos mesmos. No presente trabalho verificou-se superioridade no número de frutos totais e comerciais para o tratamento com uma haste/planta sem a eliminação dos mente $1,8 \mathrm{~m}$ de altura.

Para a variável produtividade total/ planta, a ausência de retirada das brotações laterais influenciou de forma significativa as plantas conduzidas com uma haste/planta. Enquanto que a retirada das brotações laterais favoreceu significativamente as plantas com três hastes/planta, o mesmo fato ocorreu para a produtividade comercial/planta. Nota-se também que à medida que se manteve um maior número de hastes para plantas podadas, ou seja, três hastes/planta, também foi verificada maior produtividade total e comercial/planta em relação às plantas podadas.

Para as variáveis comprimento, diâmetro e massa média dos frutos (MMF), houve efeito significativo do fator poda das brotações laterais (Tabela 2). Onde foi verificado aumento no comprimento, diâmetro e MMF de pepino japonês nos tratamentos com poda, evidenciando o fato verificado por Valantin et al. (2006) e Queiroga et al. (2008), que o carregamento de frutos em cucurbitáceas afeta a taxa de crescimento e o seu tamanho final, uma vez que toda expansão celular ocorre após a antése, enquanto que a divisão celular continua em baixa taxa. Portanto, o número de células no final da antése é fator chave que contribui para com o tamanho final dos frutos, principalmente por causa de sua influência na habilidade dos frutos para atraírem assimilados. Valantin et al. (2006) ressaltaram ainda que variações no tamanho final do fruto podem ser interpretadas como consequência de dois processos: a força do dreno durante o período de divisão celular e a taxa de crescimento do fruto durante a expansão celular.

Segundo Valantin et al. (2006), no meloeiro, quando se aumenta o número de frutos por planta, a demanda dos frutos por fotoassimilados se eleva, instalando-se forte competição entre os frutos, afetando o crescimento desses. Assim, maior número de frutos na planta reduz a massa média do fruto. Estes resultados corroboram com aqueles encontrados por Seabra Júnior et al. (2003) em melancia, Barni et al. (2003), Fagan et al. (2006) e Duarte \& Peil (2010) trabalhando com meloeiro, os quais constataram que a competição 
por fotoassimilados pelos frutos se eleva, instalando-se uma forte competição por assimilados entre esses, afetando o tamanho final do fruto.

O comprimento dos frutos do pepino japonês Tsuyataro apresentou efeito significativo para o fator de manejo com diferentes números de hastes/planta, onde os manejos com uma e duas hastes por planta, apresentaram 25,1 e 25,0 cm de comprimento de fruto respectivamente, e esses por sua vez foram maiores em relação ao manejo com três hastes, com $24,3 \mathrm{~cm}$ de comprimento médio do fruto (Tabela 3).

Na relação comprimento e diâmetro do fruto não foi verificado efeito significativo da interação do fator poda dos ramos laterais e dos diferentes manejos de condução do número de hastes, bem como os fatores isolados (Tabelas $2 \mathrm{e}$ $3)$. No presente trabalho foi verificada uma relação de comprimento e diâmetro do fruto de 7,1. Cardoso (2007) relatou que o fato de se colher os frutos com tamanho padrão comercial atingido antes do potencial máximo de crescimento dos frutos, levou a pequenas diferenças entre os frutos, tal como observado no presente trabalho. O mesmo autor relatou ainda que a relação comprimento e diâmetro do fruto é uma característica que independe do ponto de colheita para pepino, pois o formato do fruto pouco se altera em vista ao processo de maturação do fruto.

A condução de uma haste/planta sem a retirada dos ramos laterais, proporciona melhores resultados para produção de pepino japonês em ambiente protegido, especialmente para quem não tem mão de obra para a poda. Já em caso de sementes de alto valor econômico, onde a economia pode ser realizada com a condução de plantas em maior número de hastes, exige-se poda principalmente para aquelas plantas com mais de duas hastes por planta, além do fato da re- moção dos ramos laterais promover o aumento no comprimento e diâmetro do fruto e consequentemente promover maior massa média dos frutos do pepineiro. Entretanto, a realização de novas pesquisas em diferentes condições, bem como manejo de diferentes espaçamentos em relação à haste/área e poda faz-se necessária para esclarecer cada vez mais os efeitos desta técnica.

\section{REFERÊNCIAS}

ANDRIOLO JL; FALCÃO LL. 2000. Efeito da poda de folhas sobre a acumulação de matéria seca e sua repartição para os frutos do tomateiro cultivado em ambiente protegido. Revista Brasileira de Agrometeorologia 8: 75-83.

BARNI V; BARNI NA; SILVEIRA JRP. 2003. Meloeiro em estufa: duas hastes é o melhor sistema de condução. Ciência Rural 33. 1039-1043.

CARDOSO AII. 2007. Avaliação de linhagens e híbrido experimentais de pepino do grupo varietal japonês sob ambiente protegido. Bragantia 66: 469-475.

CEASAMINAS - Centrais de abastecimento de Minas Gerais S.A. Agroqualidade. 2010. Classificação de hortaliças. Pepino. http://minas.ceasa.mg.gov.br/ceasanovo /agroqualidadepepino.asp. acessado em 05/10/2010.

DALLACORT R; MARTINS JA; INOUE MH; FREITAS PSL; COLETTI AJ. 2011. Distribuição das chuvas no município de Tangará da Serra, médio norte do Estado de Mato Grosso, Brasil. Acta Scientiarum. Agronomy 33: 193-200.

DUARTE TS; PEIL RMN; MONTEZANO EM. 2008. Crescimento de frutos do meloeiro sob diferentes relações fonte:deno. Horticultura Brasileira 26: 342-347.

DUARTE TS; PEIL RMN. 2010. Relações fonte:dreno e crescimento vegetativo do meloeiro. Horticultura Brasileira 28: 271-276.

EMBRAPA - Centro Nacional de Pesquisa de Solos. 2006. Sistema brasileiro de classificação de solos. Rio de Janeiro: EMBRAPA Solos. 306p.

FAGAN EB; MEDEIROS SLP; SIMON J; LUZ GL; BORCIONI E; JASNIEWICZ LR; CASAROLI D; MAFRON PA. 2006. Evolução e partição de massa seca do meloeiro em hidroponia. Acta Scientiarum. Agronomy 28: 165-172.
FERREIRA DF. 2008. SISVAR: um programa para análises e ensino de estatística. Revista Symposium 6: 36-41.

FILGUEIRA FAR. 2008. Novo manual de olericultura: agrotecnologia moderna na produção e comercialização de hortaliças. Viçosa: UFV. 421p.

FONTES PCR; PUIATTI M. 2005. Cultura do Pepino. In: FONTES PCR (ed). Olericultura: teoria e prática. Viçosa: FONTES PCR. 486p.

IBGE - Instituto Brasileiro de Geografia e Estatística. 2006. Censo agropecuário: Brasil, Grandes Regiões e Unidades da Federação. Rio de Janeiro: IBGE. 777p.

LALLA JG; LAURA VA; SEABRA JÚNIOR S; CARDOSO AII. 2010. Capacidade combinatória e heterose de linhagens de pepino do grupo japonês para caracteres de produção. Horticultura Brasileira 28: 337-343.

MARTINS SR; FERNANDES HS; POSTINGHER D; SCHWENGBER JE; QUINTANILLA LF.1995. Avaliação da cultura do pepino (Cucumis sativus L.), cultivado em estufa plástica, sob diferentes tipos de poda e arranjos de plantas. Revista Brasileira de Agrociência 1: 30-33.

PEIL RMN; GÁLVEZ JL. 2005. Reparto de materia seca como factor determinante de la producción de las hortalizas de fruto cultivadas em invernadero. Revista Brasileira Agrociência 11: 05-11.

PEREIRA FHF; NOGUEIRA ICC; PEDROSA JF; NEGREIROS MZ; BEZERRA NETO F. 2003. Poda da haste principal e densidade de cultivo sobre a produção e qualidade de frutos em híbridos de melão. Horticultura Brasileira 21: 191-196.

QUEIROGA, RCF; PUIATTI, M; FONTES PCR; CECON PR. 2008. Produtividade e qualidade de frutos de meloeiro variando número de frutos e de folhas por planta. Horticultura Brasileira. 26: 209-215.

SCHVAMBACH JL; ANDRIOLO JL; HELDWEIN AB. 2002. Produção e distribuição da matéria seca do pepino para conserva em diferentes populações de plantas. Ciência Rural 32: 35-41.

SEABRA JÚNIOR S; PANTANO SC; HIDALGO AF; RANGEL MG; CARDOSO AII. 2003. Avaliação do número e posição do fruto de melancia produzido em ambiente protegido. Horticultura Brasileira 21: 708-711.

TAIZ L; ZEIGER E. 2004. Fisiologia vegetal. Porto Alegre: Artmed. 719p.

VALANTIN M; VAISSIERE BE; GARY C; ROBIN P. 2006. Source-sink balance affects reproductive development and fruit quality in cantaloupe melon. Journal of Horticultural Science \& Biotechnology 81: 105-117. 